\title{
Recent Developments in the Management of Acute Pancreatitis
}

\author{
C.J . McKay \\ West of Scotland Pancreatic Unit, Royal Infirmary, Glasgow, UK
}

\section{Key Words}

Acute Pancreatitis - Pancreatic necrosis .

Minimally-invasive surgery

In the past decade, many advances have been made in our understanding of the pathophysiology of acute pancreatitis and its complications and several large clinical trials have been carried out which, it was hoped, would lead to specific treatments for this condition. During this period, there has been a steady rise in the incidence of acute pancreatitis and overall mortality has remained unchanged at around $8 \%[1]$.

\section{Medical Management}

Attempts to introduce specific treatments for acute pancreatitis fall into the following categories: (a) Inhibition of pancreatic secretion; (b) Prevention of infection; (c) Inhibition of the inflammatory response, and (d) ERCP \pm ES.

\begin{tabular}{ll}
\hline KARGER & ( 2002 S. Karger AG, Basel \\
0253-4886/02/0192-0129\$18.50/0 \\
$\begin{array}{l}\text { Fax +4161306 12 34 } \\
\text { E-Mail karger@karger.ch } \\
\text { www.karger.com }\end{array}$ & $\begin{array}{l}\text { Accessible online at: } \\
\text { www.karger.com/journals/dsu }\end{array}$
\end{tabular}

\section{Inhibition of Pancreatic Secretion}

It has for many years been considered important in the treatment of acute pancreatitis to 'rest the pancreas' and the standard approach of withholding diet until clinical resolution was based on this philosophy. Pharmacological attempts to suppress pancreatic function have included glucagon, somatostatin and, more recently, the somatostatin analogue octreotide. There have now been five randomized trials of octreotide in the management of acute pancreatitis reported in the literature. The first of these randomized just 19 patients [2], the main finding being a reduction in analgesic requirements in the octreotidetreated group. Next came a study from Israel [3], recruiting 51 patients with predicted severe acute pancreatitis to treatment with octreotide or standard supportive care. The overall complication rate was lower in the octreotide group and hospital stay was shorter. Unfortunately, 25\% of the patients were excluded from analysis due to incomplete data and this 'preliminary report' was never followed by a report on the completed study. In the West of Scotland Study [4], 58 patients with predicted severe acute pancreatitis were recruited. This was the first study to be conducted in a double-blind, placebo-controlled fashion and in contrast to the previous reports, there was

Colin J. McKay

West of Scotland Pancreatic Unit, Royal Infirmary

Glasgow G31 2ER (UK)

Tel. +44 141 8001977, Fax +44 141 5523229, E-Mail c.j.mckay@clinmed.gla.ac.uk 
no evidence of a beneficial effect of octreotide on outcome. A further nonblinded, small study was reported from Turkey [5] but in the same year, the definitive study was published. A multicentre trial from Germany [6], conducted with the support of the drug manufacturer, recruited 302 patients from 32 hospitals but failed to demonstrate any effect of octreotide on a number of clinical endpoints. Following this report, there can be no justification for the use of octreotide in the treatment of acute pancreatitis.

\section{Antibiotics}

In patients who survive the early, systemic complications of acute pancreatitis, secondary infection of pancreatic necrosis is the most important late complication. Infection occurs in $30-40 \%$ of patients with pancreatic necrosis [7] and is responsible for the majority of late deaths from acute pancreatitis. There has been considerable interest in the potential role of antibiotic prophylaxis in patients with pancreatic necrosis and four randomized trials have addressed this issue.

Pederzoli et al. [8] reported the results of a multicentre Italian study which recruited 74 patients with necrotizing pancreatitis. Patients were randomized to receive imipen$\mathrm{em}, 0.5 \mathrm{~g}$ three times daily or standard treatment. The use of imipenem was associated with a reduction in secondary pancreatic infection from 30 to $12 \%$ and a reduction in extrapancreatic sepsis from 49 to $15 \%$. Three deaths occurred in each group.

In a single-centre study of similar design, Sainio et al. [9] randomized 60 patients with pancreatic necrosis to receive cefuroxime, $1.5 \mathrm{~g}$ three times daily or standard treatment. This study, commonly interpreted as further evidence in support of antibiotic therapy, had findings that contrasted sharply with those of the Italian trial [8]. No difference was observed in the incidence of secondary pancreatic infection but there was a significant reduction in mortality associated with cefuroxime prophylaxis. Interpretation of these results is made more difficult by the fact that $70 \%$ of those in the placebo arm subsequently received antibiotic therapy and the majority of those in the cefuroxime arm required a change in antibiotics.

As the majority of secondary pancreatic infections are Gram negative in origin, it is widely believed that the source of these organisms is translocation from the intestinal tract. Luiten et al. [10] assessed the effect of selective gut decontamination using norflocacin, colistin and amphotericin on 102 patients recruited from 16 hospitals over a 3-year period. Once again, there was a reduction in the rate of secondary pancreatic infection in the group randomized to selective gut decontamination compared with controls (18\% compared with $38 \%$ ) and this was associated with a significant reduction in late mortality from 23 to $7 \%$. Early mortality was unchanged. Unfortunately, all patients in the gut decontamination group also had parenteral cefotaxime and the relative contribution of the parenterally administered antibiotics in this study is not clear.

A randomized comparison of imipenem and pefloxacin in patients with necrotizing acute pancreatitis was reported by Bassi et al. [11] following a 6-year, multicentre study. Pefloxacin, which has limited activity against the range of organisms commonly associated with infected pancreatic necrosis, was associated with more secondary pancreatic infection than imipenem. The imipenem group had a $10 \%$ infection rate which is similar to the $12 \%$ found by Pederzoli et al. [8] using the same antibiotic prophylaxis.

From these data, it is reasonable to conclude that prophylactic antibiotic therapy with a broad-spectrum agent with adequate pancreatic tissue penetration (such as imipenem) will reduce the rate of secondary pancreatic infection in patients with pancreatic necrosis. At present there are no data to guide decisions on the optimal timing and duration of antibiotic treatment. The selection of patients for antibiotic prophylaxis is also difficult, as CT scans to detect the presence of pancreatic necrosis are not routinely performed early in acute pancreatitis. From published data it appears that systemic antibiotics are as effective as selective gut decontamination in prophylaxis of secondary pancreatic infection and have the benefit of ease of administration.

\section{Anticytokine Therapy - Lexipafant}

In recent years there has been much interest in the use of the platelet-activating factor (PAF) antagonist, lexipafant, in the treatment of patients with acute pancreatitis. PAF is an inflammatory mediator released from many inflammatory cells and is considered to play an important role in the priming and amplification of the inflammatory response. Lexipafant is a PAF receptor antagonist which had shown promise in studies in experimental pancreatitis. The first clinical trial was reported by Kingsnorth et al. [12]. This was a randomized comparison of lexipafant, $60 \mathrm{mg}$ daily for 3 days, with placebo in 83 unselected patients with acute pancreatitis. The main findings of this 
study were a reduction in levels of the pro-inflammatory cytokines, interleukin- 6 and interleukin- 8 , with lexipafant treatment and an associated reduction in organ failure scores at the end of the 3-day treatment period. Our own group [13] reported the results of a second randomized trial, recruiting 50 patients with predicted severe acute pancreatitis, which broadly confirmed the findings of the previous study. We found a significantly greater reduction in organ failure scores after 7 days of treatment with $100 \mathrm{mg} /$ day of lexipafant when compared with placebo. A common finding in both studies was that no patients in the treatment groups developed significant organ failure following admission to hospital. These encouraging results led to a multicentre UK study [14] that recruited 290 patients with predicted severe attacks from 78 hospitals. The primary endpoint was the incidence of complications and secondary endpoints were reduction in organ failure scores and plasma markers of the inflammatory response. Unfortunately, $75 \%$ of patients who had early organ failure had evidence of this prior to study entry and the primary study endpoint was therefore invalidated. There was a significant reduction in organ failure scores at day 3 in the treatment group but by day 7 , at completion of the trial infusion, there was no difference between groups. Of further concern was the fact that there was no difference in the incidence of newly developed organ failure. There was no difference in mortality overall but a subgroup analysis, comparing mortality in patients entering the study within $48 \mathrm{~h}$ of symptom onset, found a significant reduction in mortality with lexipafant treatment. There followed an international, multicentre study that recruited 1,500 patients randomized to receive lexipafant $100 \mathrm{mg}$ daily, lexipafant $10 \mathrm{mg}$ daily or placebo. This study recruited only those patients with symptoms of $<48 \mathrm{~h}$ duration and again was restricted to those with predicted severe attacks. Unfortunately, no difference in mortality or complication rate was observed between these groups and further development of lexipafant in acute pancreatitis has been abandoned.

\section{ERCP}

In the absence of an effective medical therapy, the main therapeutic question in the early phase of acute pancreatitis relates to the necessity for ERCP. Experimental studies indicate that the duration of biliary and pancreatic obstruction relates to the severity of acute pancreatitis and that early decompression can lessen the degree of pancreatic injury [15]. There have now been four random- ized trials reported which have addressed this issue. In the first study, from the UK, 121 patients with gallstone pancreatitis were randomized to receive conservative treatment or ERCP with endoscopic sphincterotomy within $72 \mathrm{~h}$ of admission [16]. 59 patients were randomized to ERCP of whom 25 were classified as having a severe attack. 62 had conventional treatment, 28 severe. In this study, there was no procedure-related morbidity confirming the safety of this procedure in expert hands. When the subgroup with predicted severe pancreatitis was studied, there was a reduction in morbidity and a trend towards a reduction in mortality in the ERCP group. A subsequent study from Hong Kong [17] broadly confirmed these findings in a group of 195 patients. In particular, there was a marked reduction in the incidence of biliary sepsis in the patients randomized to ERCP and once again the effect was most obvious in the predicted severe group. These studies have been criticized for including patients with possible cholangitis and the Hong Kong study in particular, where bile duct stones and cholangitis are common, may reflect the effect of early endoscopic sphincterotomy on patients with coexisting cholangitis and acute pancreatitis.

A multicentre German study randomized 238 patients to early ERCP or no treatment [18]. In this study, patients with jaundice were excluded and no benefit from ERCP was seen. Conversely, an unexplained increased in respiratory complications was observed in the ERCP group. This study has come in for much criticism, mainly because 19 of the 22 centres recruited fewer than 2 patients per year to the study suggesting either significant selection bias or limited experience with ERCP in acute pancreatitis in the majority of centres. It does however lend weight to the suggestion that ERCP and endoscopic sphincterotomy is of little value in the absence of jaundice or cholangitis.

In an as yet unpublished study from Poland [19], 280 patients with acute pancreatitis underwent early ERCP. Patients with bile duct calculi underwent endoscopic sphincterotomy while the remainder were randomized to sphincterotomy or no treatment. Significant reductions in morbidity and mortality were seen in the group randomized to endoscopic sphincterotomy, suggesting that this is beneficial even in the absence of bile duct stones. Unfortunately this study, which was presented 5 years ago, has never been published in a peer-reviewed journal and it is therefore impossible to make recommendations based on its findings.

At the present time, the evidence strongly supports early ERCP with endoscopic sphincterotomy for all patients 
Table 1. Mortality following surgery for proven infected pancreatic necrosis

\begin{tabular}{lcc}
\hline Group (first author) & Patients & Mortality, \% \\
\hline Beger, 1999 [21] & 93 & 26 \\
Fernandez-del Castillo, 1998 [22] & 36 & 8.3 \\
Branum 1998 [23] & 42 & 7 \\
Farkas, 1996 [24] & 123 & 7 \\
Fugger, 1995 [25] & 106 & 36 \\
Bradley, 1993 [26] & 71 & 15 \\
Pederzoli, 1990 & 93 & 29 \\
\hline
\end{tabular}

with gallstone pancreatitis who are jaundiced or in whom there is a suspicion of cholangitis. In the remainder of patients, controversy remains.

\section{Surgery}

The main indication for surgery in acute pancreatitis is infected pancreatic necrosis. Infection occurs in approximately $30-40 \%$ of patients with pancreatic necrosis [8, $11,20]$. It is rare in the first week of an attack but reaches a peak in the third week [20] and is suspected when a patient has signs of sepsis or evidence of new or continuing MODS after the first week of an attack. In such cases, a CT scan is carried out, with intravenous and oral contrast, and the presence of significant areas of pancreatic necrosis confirmed. A fine needle aspirate is taken from the necrotic area under $\mathrm{CT}$ guidance and submitted for immediate Gram stain. If infection is confirmed, pancreatic debridement is usually carried out within $24 \mathrm{~h}$. Recent published results using this approach are summarized in table 1.

The reasons for the disparity in clinical outcome are not clear but may reflect different referral patterns, case selection or as yet unexplained differences in patient management. It is clear however that following surgery for infected pancreatic necrosis, there is significant surgical morbidity and mortality remains high.

In recent years there has been interest in attempting to reduce the morbidity associated with infected pancreatic necrosis by adopting a number of minimally invasive approaches.

\section{Endoscopic Therapy}

Successful, endoscopic drainage of infected pancreatic necrosis has been described by Baron et al. [27]. In their initial report, 11 patients with symptomatic pancreatic collections, associated with pancreatic necrosis, were treated by endoscopic transgastric drainage with two pigtail stents, augmented in later cases by nasocavitary lavage. The technique is widely used for the drainage of simple pancreatic pseudocysts but was previously considered contraindicated in the presence of significant necrosis. These patients were however a very select group, all with late, organized collections. The authors acknowledge that these patients are distinct from those with acute pancreatic necrosis earlier in the course of acute pancreatitis [28]. A further consideration is that 4 patients $(36 \%)$ developed infection of a collection which was sterile prior to intervention, 1 of whom subsequently required surgical debridement. There was 1 case of iatrogenic bleeding and 1 gastric perforation underlining the potential dangers of this approach.

\section{Percutaneous Drainage}

Percutaneous drainage has become the standard approach to the management of septic collections in the postoperative period but few would advocate its use in the context of infected pancreatic necrosis, as the presence of solid and semisolid necrotic tissue within the collection inevitably leads to failure [29]. Freeny et al. [30] have described a modification of percutaneous drainage, where large-bore catheters are placed and combined with repeated vigorous lavage. In their series of 34 patients with infected pancreatic necrosis, 16 (49\%) had resolution of sepsis without surgery. Only 8 patients (24\%) required surgery due to failure of resolution of sepsis and a further patient had surgery for bleeding.

A similar technique was reported by Echenique et al. [31], with the modification that suction catheters and stone retrieval baskets were used, in addition to large-bore drains and lavage, to remove solid debris. Twenty carefully selected patients had successful resolution of infected pancreatic necrosis using this approach.

\section{Laparoscopic Approach}

The value of percutaneous drainage, even with the modifications described above, is limited by the presence 
of solid necrotic tissue which, if not removed, acts as a nidus for continuing sepsis. Laparoscopic techniques have the advantage that necrotic debris can be removed under vision, allowing a more complete debridement. Alverdy et al. [32] recently described such an approach in 2 patients with infected pancreatic necrosis. In the first case, two open necrosectomies had been performed and the laparoscopic approach was used to deal with the residual collections. Trochars were placed over the existing percutaneous drains and initial blind debridement was followed by debridement under visual control using a $30^{\circ}$ laparoscope. The second patient had primary debridement carried out using a laparoscopic technique, with percutaneous drains being placed in the collection under radiological guidance and laparoscopic trochars inserted over these drains. Both patients required repeated procedures but had a satisfactory outcome.

Our own group has reported a new technique for the management of infected pancreatic necrosis which we have applied in a sequential group of patients [33]. Following placement of a percutaneous drain in the collec- tion, patients were taken to theatre and under general anaesthetic, the track dilated and the collection explored with a rigid nephroscope. Through the working channel of this instrument, forceps were used to debride the loose necrotic tissue. Continuous lavage with sterile dialysis fluid facilitated the debridement. Postoperative lavage was continued through a dual-channel drain. Encouraging results were obtained in a group of 10 unselected patients, 8 of whom survived. All had proven infected pancreatic necrosis between 19 and 187 days (median 24 days) from symptom. An interesting observation was that 5 of these patients were managed without postoperative use of the intensive care unit. We are continuing to evaluate this technique and plan a randomized comparison with the open approach.

The management of severe acute pancreatitis remains a formidable challenge and, if anything, the management decisions have become more complex in recent years. Early involvement of a specialist team, including radiologists, endoscopists, intensivists and experienced surgeons, is essential if patient outcome is to be optimized.

\section{References}

1 McKay CJ, Evans S, Sinclair M, Carter CR, Imrie CW: High early mortality rate from acute pancreatitis in Scotland, 1984-1995. Br J Surg 1999;86:1302-1305.

2 Beechey-Newman N: Controlled trial of highdose octreotide in treatment of acute pancreatitis. Evidence of improvement in disease severity. Dig Dis Sci 1993;38:644-647.

3 Paran H, Neufeld D, Mayo A, Shwartz I, Singer P, Kaplan O, Skornik Y, Klausner J, Freund U: Preliminary report of a prospective randomized study of octreotide in the treatment of severe acute pancreatitis. J Am Coll Surg 1995; 181:121-124.

4 McKay C, Baxter J, Imrie C: A randomized, controlled trial of octreotide in the management of patients with acute pancreatitis. Int $\mathbf{J}$ Pancreatol 1997;21:13-19.

5 Karakoyunlar O, Sivrel E, Tanir N, Denecli AG: High-dose octreotide in the management of acute pancreatitis. Hepatogastroenterology 1999;46:1968-1972.

6 Uhl W, Büchler MW, Malfertheiner P, Beger HG, Adler G, Gaus W, Vogel R, Schmid S, Rau B, Bruch HP, et al: A randomised, doubleblind, multicentre trial of octreotide in moderate to severe acute pancreatitis. Gut 1999;45: 97-104.

7 Beger HG, Rau B, Mayer J, Pralle U: Natural course of acute pancreatitis. World J Surg 1997;21:130-135.
8 Pederzoli P, Bassi C, Vesentini S, Campedelli A: A randomized multicenter clinical trial of antibiotic prophylaxis of septic complications in acute necrotizing pancreatitis with imipenem. Surg Gynecol Obstet 1993;176:480-483.

9 Sainio V, Kemppainen E, Puolakkainen P, Taavitsainen M, Kivisaari L, Valtonen V, Haapiainen R, Schroder T, Kivilaakso E: Early antibiotic treatment in acute necrotising pancreatitis. Lancet 1995;346:663-667.

10 Luiten EJT, Hop WCJ, Lange JF, Bruining, HA: Controlled clinical trial of selective decontamination for the treatment of severe acute pancreatitis. Ann Surg 1995;222:57-65.

11 Bassi C, Falconi M, Talamini G, Uomo G, Papaccio G, Dervenis C, Salvia R, Minelli EB, Pederzoli P: Controlled clinical trial of pefloxacin versus imipenem in severe acute pancreatitis. Gastroenterology 1998;115:1513-1517.

12 Kingsnorth AN, Galloway SW, Formela LJ: Randomized, double-blind phase II trial of lexipafant, a platelet-activating factor antagonist, in human acute pancreatitis. Br J Surg 1995;82: 1414-1420.

13 McKay CJ, Curran F, Sharples C, Baxter JN, Imrie CW: Prospective placebo-controlled randomized trial of lexipafant in predicted severe acute pancreatitis. Br J Surg 1997;84:12391243.

14 Imrie CW, McKay CJ: The scientific basis of medical therapy of acute pancreatitis: Could it work, and is there a role for lexipafant? Gastroenterol Clin North Am 1999;28:591-599.
15 Runzi M, Saluja A, Lerch MM, Dawra R, Nishino H, Steer, ML: Early ductal decompression prevents the progression of biliary pancreatitis: An experimental study in the opossum. Gastroenterology 1993;105:157-164.

16 Neoptolemos JP, London NJ, James D, CarrLocke DL, Bailey IA, Fossard DP: Controlled trial of urgent endoscopic retrograde cholangiopancreatography and endoscopic sphincterotomy versus conservative treatment for acute pancreatitis due to gallstones. Lancet 1988; ii:979-983.

17 Fan ST, Lai ECS, Mok FPT, Lo CM, Zheng SS, Wong J: Early treatment of acute biliary pancreatitis by endoscopic papillotomy. N Engl J Med 1993;328:228-232.

18 Fölsch UR, Nitsche R, Ludtke R, Hilgers RA, Creutzfeldt W: Early ERCP and papillotomy compared with conservative treatment for acute biliary pancreatitis. N Engl J Med 1997; 336:237-242.

19 Nowak A, Nowakowska-Dulawa E, Marek T, et al: Final results of the prospective, randomized, controlled study on endoscopic sphincterotomy versus conventional management in acute biliary pancreatitis (abstract). Gastroenterology 1995;108:A380-A380.

20 Beger HG, Bittner R, Block S, Büchler M: Bacterial contamination of pancreatic necrosis. A prospective clinical study. Gastroenterology 1986;91433-438. 
21 Beger HG, Isenmann R: Surgical management of necrotizing pancreatitis. Surg Clin North Am 1999;79:783-800.

22 Fernandez-del Castillo C, Rattner DW, Makary MA, Mostafavi A, McGrath D, Warshaw AL: Debridement and closed packing for the treatment of necrotizing pancreatitis. Ann Surg 1998;228:676-684.

23 Branum G, Galloway J, Hirchowitz W, Fendley M, Hunter J: Pancreatic necrosis: Results of necrosectomy, packing, and ultimate closure over drains. Ann Surg 1998;227:870-877.

24 Farkas G, Marton J, Mandi Y, Szederkenyi E: Surgical strategy and management of infected pancreatic necrosis. Br J Surg 1996;83:930933.

25 Fugger R, Gotzinger P, Sautner T, Mittlbock M, Rogy M, Adamer K, Fritsch A: Necrosectomy and laparostomy - A combined therapeutic concept in acute necrotising pancreatitis. Eur J Surg 1995;161:103-107.
26 Bradley I: A fifteen year experience with open drainage for infected pancreatic necrosis. Surg Gynecol Obstet 1993;177:215-222.

27 Baron TH, Thaggard WG, Morgan DE, Stanley RJ: Endoscopic therapy for organized pancreatic necrosis. Gastroenterology 1996;111: 755-764.

28 Baron TH, Morgan DE: Organized pancreatic necrosis. Definition, diagnosis and management. Gastroenterol Int 1997;10:167-178.

29 Rotman N, Mathieu D, Anglade MC, Fagniez PL: Failure of percutaneous drainage of pancreatic abscesses complicating severe acute pancreatitis. Surg Gynecol Obstet 1992;174: 141-144.

30 Freeny PC, Hauptmann E, Althaus SJ, Traverso LW, Sinanan: Percutaneous CT-guided catheter drainage of infected acute necrotizing pancreatitis: Techniques and results. Am J Roentgenol 1998;170:969-975.
31 Echenique AM, Sleeman D, Yrizarry J, Scagnelli T, Guerra JJ Jr, Casillas, VJ, Huson $\mathrm{H}$, Russell E: Percutaneous catheter-directed debridement of infected pancreatic necrosis: Results in 20 patients. J Vasc Interv Radiol 1998; 9:565-571.

32 Alverdy J, Vargish T, Desai T, Frawley B, Rosen B: Laparoscopic intracavitary debridement of peripancreatic necrosis: Preliminary report and description of the technique. Surgery 2000 ; 127:112-114

33 Carter CR, McKay CJ, Imrie CW: Percutaneous necrosectomy and sinus tract endoscopy in the management of infected pancreatic necrosis: An initial experience. Ann Surg 2000; 232:175-180 